\title{
Long-term outcome of intraoperative radiofrequency ablation for hepatocellular carcinoma and its efficacy as a primary treatment
}

\author{
Jongduk Kwon, Kwang-Sik Chun, In-Sang Song, Seok-Hwan Kim, and Sunjong Han
}

Department of Surgery, Chungnam National University Hospital, Daejeon, Korea

\begin{abstract}
Backgrounds/Aims: We conducted this study to identify long-term outcomes following intraoperative radiofrequency ablation (IO-RFA) for hepatocellular carcinoma (HCC) and to reveal independent prognostic factors for survival. Methods: From December 1998 to February 2019, 183 patients underwent IO-RFA for HCC. These patients were divided into two groups according to whether RFA was done as a first-line (1-RFA group, $n=106)$ or secondary-line (2-RFA group, $n=77$ ) treatment. Furthermore, we compared the survival outcomes between the 1-RFA and 2-RFA groups. Results: There were no significant differences in type of surgical approaches between the two groups $(p=0.079)$. The number of tumors and largest tumor size were not significantly different between the two groups. Overall recurrence rate was 53\%, and the 2-RFA group showed a higher recurrence rate (46.2\% in 1-RFA group versus $62.3 \%$ in $2-$ RFA group; $p=0.031$ ). The 5-year overall survival (OS) and disease-free survival (DFS) rates of all the patients were $75.2 \%$ and $27.9 \%$, respectively. The OS and DFS rates were significantly higher in the 1-RFA group. The 5-year OS rates were $83.6 \%$ and $64.9 \%$ in the 1 -RFA and 2-RFA groups, respectively $(p=0.010)$, whereas the 5 -year DFS rates were $32.2 \%$ and $21.6 \%$, respectively $(p=0.012)$. On multivariate analysis, HBV-LC, 2-RFA, recurrence, and postoperative complications were independent predictive factors for survival. Conclusions: Therapeutic outcomes of IO-RFA were comparable to those of surgical resection. Additionally, 1-RFA might be an alternative treatment for naïve HCC in patients with uncompensated liver function and severe comorbidities. (Ann Hepatobiliary Pancreat Surg 2020;24:24-32)
\end{abstract}

Key Words: Hepatocellular carcinoma; Radiofrequency ablation; First-line; Second-line; Outcome

\section{INTRODUCTION}

Hepatocellular carcinoma (HCC) is currently the 5th most frequent cancer and a leading cause of cancer-related mortality worldwide. ${ }^{1-3}$ Although potentially curative treatment options, such as hepatic resection and liver transplantation, are associated with significant survival benefits, only $10-30 \%$ of patients with HCC are eligible for surgery at the time of diagnosis. ${ }^{4}$ Radiofrequency ablation (RFA) has been proposed as an alternative treatment owing to its safety and effectiveness for patients with early to intermediate stage HCC. ${ }^{5,6}$ A meta-analysis of 31 studies comparing 16,103 patients who received either ablation or hepatic resection showed comparable longterm outcomes in lesions $\leq 2 \mathrm{~cm}$ in size, with significantly fewer complications and shorter hospital stay durations associated with ablation. ${ }^{7}$ Furthermore, for those pa- tients ineligible for surgery, ablation is a potentially curative modality, which has demonstrated a significant clinical efficacy with an overall 5-year survival rate between $68 \%$ and $76 \%$ for tumors $\leq 5 \mathrm{~cm}$ in size. ${ }^{8,9}$ However, other studies showed that approximately $68.9 \%$ of patients had tumor recurrence after RFA, which is higher than the rate for liver transplantation and surgical resection. ${ }^{10-12}$

We conducted this study to identify long-term outcomes following intraoperative RFA (IO-RFA) and reveal independent prognostic factors for survival. Furthermore, we classified and compared survival outcomes according to whether the patients were treated with RFA as the first-line or second-line treatment.

\section{PATIENTS AND METHODS}

From December 1998 to February 2019, a total of 541

Received: October 8, 2019; Revised: October 10, 2019; Accepted: October 23, 2019

Corresponding author: Kwang-Sik Chun

Department of Surgery, Chungnam National University Hospital, 282 Munhwa-ro, Jung-gu, Daejeon 35015, Korea Tel: +82-42-280-7175, Fax: +82-42-257-8024, E-mail: oxali@daum.net

Copyright (C) 2020 by The Korean Association of Hepato-Biliary-Pancreatic Surgery

This is an Open Access article distributed under the terms of the Creative Commons Attribution Non-Commercial License (http://creativecommons.org/ censes/by-nc/4.0) which permits unrestricted non-commercial use, distribution, and reproduction in any medium, provided the original work is properly cited. Annals of Hepato-Biliary-Pancreatic Surgery - pISSN: 2508-5778 - elSSN: 2508-5859 
patients underwent surgery for HCC at our institution. Among them, 342 patients underwent surgical resection, and 16 patients who underwent surgical resection with IO-RFA were excluded. The remaining 183 patients who

Table 1. Demographics and clinicopathologic data

\begin{tabular}{|c|c|c|c|c|}
\hline & IO-RFA $(n=183)$ & 1-RFA $(n=106)$ & 2-RFA $(n=77)$ & $p$ value \\
\hline Sex (male:female) & $136(74.3): 47(25.7)$ & $72(67.9): 34(32.1)$ & 64 (83.1):13 (16.9) & 0.020 \\
\hline Age (years, mean \pm SD) & $63.3 \pm 9.11$ & $64.3 \pm 8.81$ & $61.9 \pm 9.4$ & 0.076 \\
\hline \multicolumn{5}{|l|}{ Co-morbidity (n, \%) } \\
\hline HTN & $74(40.4)$ & $38(35.8)$ & $36(46.8)$ & 0.138 \\
\hline $\mathrm{DM}$ & $61(33.3)$ & $34(32.1)$ & $27(35.1)$ & 0.672 \\
\hline \multicolumn{5}{|l|}{ Chronic liver disease } \\
\hline HBV-LC & $113(61.7)$ & $62(58.5)$ & $51(66.2)$ & 0.287 \\
\hline HCV-LC & $29(15.8)$ & $20(18.9)$ & $9(11.7)$ & 0.189 \\
\hline Alc-LC & $44(24)$ & $26(24.5)$ & $18(23.4)$ & 0.857 \\
\hline Idiopathic LC & $5(2.7)$ & $3(2.8)$ & $2(2.6)$ & 1.000 \\
\hline $\mathrm{Tb}$ & $8(4.4)$ & $2(1.9)$ & $6(7.8)$ & 0.071 \\
\hline Other abdominal op & $19(10.4)$ & $12(11.3)$ & $7(9.1)$ & 0.625 \\
\hline \multicolumn{5}{|l|}{ Previous Tx for $\operatorname{HCC}(\mathrm{n}, \%)$} \\
\hline Hepatectomy & $20(10.9)$ & $2(1.9)$ & $18(23.4)$ & $<0.001$ \\
\hline TACE & $79(43.2)$ & $13(12.3)$ & $66(85.7)$ & $<0.001$ \\
\hline Percutaneous RFA & $26(14.2)$ & $15(14.2)$ & $11(14.3)$ & 0.979 \\
\hline Intraoperative RFA & $30(16.4)$ & $16(15.1)$ & $14(18.2)$ & 0.578 \\
\hline \multicolumn{5}{|l|}{ Laboratory findings } \\
\hline $\mathrm{Hb}$ & $13.5 \pm 1.94$ & $13.4 \pm 1.94$ & $13.5 \pm 1.95$ & 0.978 \\
\hline Plt & $115 \pm 48.75$ & $119.1 \pm 50$ & $109.5 \pm 46.7$ & 0.187 \\
\hline Alb & $3.78 \pm 0.47$ & $3.8 \pm 0.52$ & $3.7 \pm 0.39$ & 0.048 \\
\hline ТВ & $1.09 \pm 0.58$ & $1.04 \pm 0.56$ & $1.16 \pm 0.61$ & 0.186 \\
\hline INR & $1.13 \pm 0.12$ & $1.12 \pm 0.13$ & $1.13 \pm 0.11$ & 0.801 \\
\hline \multicolumn{5}{|l|}{ Tumor marker } \\
\hline AFP & $78.3 \pm 243.2$ & $84.7 \pm 254.7$ & $70.1 \pm 229$ & 0.702 \\
\hline PIVKA II & $72.9 \pm 189.0$ & $51.3 \pm 77.25$ & $99.5 \pm 268.61$ & 0.207 \\
\hline ICG $15 \mathrm{~min}$ & $27 \pm 15.2$ & $27 \pm 14.6$ & $28 \pm 16.6$ & 0.935 \\
\hline Operation type (n, \%) & & & & 0.079 \\
\hline Laparoscopic & $163(89.1)$ & $95(89.6)$ & $68(89.5)$ & \\
\hline Open & $11(6)$ & $8(7.5)$ & $3(3.9)$ & \\
\hline Open conversion & $6(3.3)$ & $1(0.9)$ & $5(6.6)$ & \\
\hline Conversion from resection & $2(1.1)$ & $2(1.9)$ & 0 & \\
\hline \multicolumn{5}{|l|}{ Tumor location (n, \%) } \\
\hline $\mathrm{S} 1$ & $3(1.6)$ & $1(0.9)$ & $2(2.6)$ & 0.574 \\
\hline $\mathrm{S} 2$ & $22(12)$ & $12(11.3)$ & $10(13)$ & 0.732 \\
\hline $\mathrm{S} 3$ & $30(16.4)$ & $18(17)$ & $12(15.6)$ & 0.801 \\
\hline $\mathrm{S} 4$ & $43(23.5)$ & $21(19.8)$ & $22(28.6)$ & 0.168 \\
\hline S5 & $35(19.1)$ & $17(16)$ & $18(23.4)$ & 0.213 \\
\hline S6 & $41(22.4)$ & $18(17)$ & $23(29.9)$ & 0.039 \\
\hline S7 & $58(31.7)$ & $33(31.1)$ & $25(32.5)$ & 0.848 \\
\hline S8 & $75(41)$ & $53(50)$ & $22(28.6)$ & 0.004 \\
\hline Number of tumors (mean \pm SD) & $1.54 \pm 0.86(1-6)$ & $1.44 \pm 0.81$ & $1.69 \pm 0.91$ & 0.052 \\
\hline $\begin{array}{l}\text { Largest tumor size } \\
\quad(\mathrm{cm}, \text { mean } \pm \mathrm{SD})\end{array}$ & $1.71 \pm 0.65(0.3-4)$ & $1.73 \pm 0.64$ & $1.67 \pm 0.66$ & 0.517 \\
\hline
\end{tabular}

IO-RFA, intraoperative radiofrequency ablation; 1-RFA, primary radiofrequency ablation; 2-RFA, secondary radiofrequency ablation; HTN, hypertension; DM, diabetes mellitus; HBV-LC, hepatitis B virus-associated liver cirrhosis; HCV-LC, hepatitis C virus-associated liver cirrhosis; Alc-LC, alcoholic liver cirrhosis; LC, liver cirrhosis; Tb, tuberculosis; Tx, treatment; HCC, hepatocellular carcinoma; TACE, transarterial chemoembolization; RFA, radiofrequency ablation; Hb, hemoglobin; Plt, platelet; Alb, albumin; TB, total bilirubin; INR, international normalized ratio; AFP, alpha fetoprotein; PIVKA II, protein induced by vitamin $\mathrm{K}$ absence or antagonist-II; ICG, indocyanine green; SD, standard deviation 
underwent IO-RFA only were finally included in the analysis. These patients were divided into two groups according to whether RFA was done as a primary or secondary treatment for HCC, which are as follows: primary RFA (1-RFA) and secondary RFA (2-RFA) groups. Primary RFA was defined as the first-line treatment for HCC after diagnosis. When the RFA was done for recurrent or incompletely treated lesions after a previous treatment, such as hepatic resection or transarterial chemoembolization (TACE), it was referred to as secondary RFA.

All patients were diagnosed and staged preoperatively by contrast computed tomography (CT) with arterial, portal, and delayed phases; magnetic resonance imaging (MRI) was also done routinely. Patients who showed typical HCC on imaging studies did not have additional biopsies. Tumor markers including alpha-fetoprotein (AFP) and protein induced by vitamin $\mathrm{K}$ absence or antagonist-II (PIVKA-II) were checked preoperatively and used for the postoperative follow-up. To evaluate the liver function, indocyanine green (ICG) test was done, and the retension rate 15 minutes after the injection was applied.

Most patients who underwent IO-RFA were laparoscopically approached, but the earlier phase of this cohort was conducted using laparotomy. Moreover, in cases wherein the localization of the tumor was not possible with intraoperative ultrasound or cases of severe adhesion due to previous surgery, the technique was converted to laparotomy. Three or four trocars were used for laparoscopic RFA. All patients underwent CT the next day of surgery to assess the adequacy of RFA.
Follow-up was updated from the electronic medical records on an outpatient. These evaluations included regularly scheduled physical examinations, CT or MRI scans, and serum level of AFP and PIVKA-II. Death, local recurrence, and distant metastasis were considered, and when no events were recorded, the patients were censored at the last date of follow-up. Overall survival (OS) and disease-free survival (DFS) were determined from the date of initial surgery to the date of death and recurrence or the last contact. For the patients whose long-term follow-up was discontinued, data from the Statistics Korea were applied.

Differences in numerical data between 1-RFA and 2-RFA groups were examined using the Chi-square test or Fischer's exact test. Student's t-test was applied to compare continuous variables. The OS and DFS rates were calculated using the Kaplan-Meier method. The log-rank test was used to analyze differences between survival curves. Cox proportional hazard regression was applied to determine independent predictive factors for survival and recurrence. A $p$-value $<0.05$ was considered statistically significant. All statistical analyses were done using SPSS software (version 24.0, IBM, New York, USA).

\section{RESULTS}

\section{Patient demographics, clinicopathologic characteristics, and surgical outcomes}

The demographics and clinicopathologic data of 183 patients who underwent IO-RFA for HCC are presented

Table 2. Surgical outcomes

\begin{tabular}{lcccc}
\hline & Intraop RFA $(\mathrm{n}=183)$ & 1-RFA $(\mathrm{n}=106)$ & 2-RFA $(\mathrm{n}=77)$ & $p$ value \\
\hline Operation duration (min, mean \pm SD) & $117.6 \pm 52.6$ & $111.4 \pm 50.7$ & $126.1 \pm 54.3$ & 0.063 \\
Postop stay (day, mean \pm SD) & $5.2 \pm 3.69(2-35)$ & $4.8 \pm 2.85$ & $5.7 \pm 4.56$ & 0.119 \\
Complications (n, \%) & $31(16.9)$ & $17(16)$ & $14(18.2)$ & 0.703 \\
$\quad$ Grade II & $20(10.9)$ & $10(9.4)$ & $10(13)$ & 0.447 \\
Grade IIIa & $3(1.6)$ & $2(1.9)$ & $1(1.3)$ & 1.000 \\
In-hospital mortality (n, \%) & $1(0.5)$ & $1(0.9)$ & 0 & 1.000 \\
Recurrence (n, \%) & $97(53)$ & $49(46.2)$ & $48(62.3)$ & $\mathbf{0 . 0 3 1}$ \\
Incomplete ablation & $6(3.3)$ & $2(1.9)$ & $4(5.2)$ & 0.241 \\
New lesion & $60(38.3)$ & $37(34.9)$ & $33(42.9)$ & 0.275 \\
Marginal recurrence & $15(8.2)$ & $7(6.6)$ & $8(10.4)$ & 0.357 \\
Distant metastasis & $5(2.7)$ & $3(2.8)$ & $2(2.6)$ & 1.000 \\
\hline
\end{tabular}

1-RFA, primary radiofrequency ablation; 2-RFA, secondary radiofrequency ablation; SD, standard deviation 

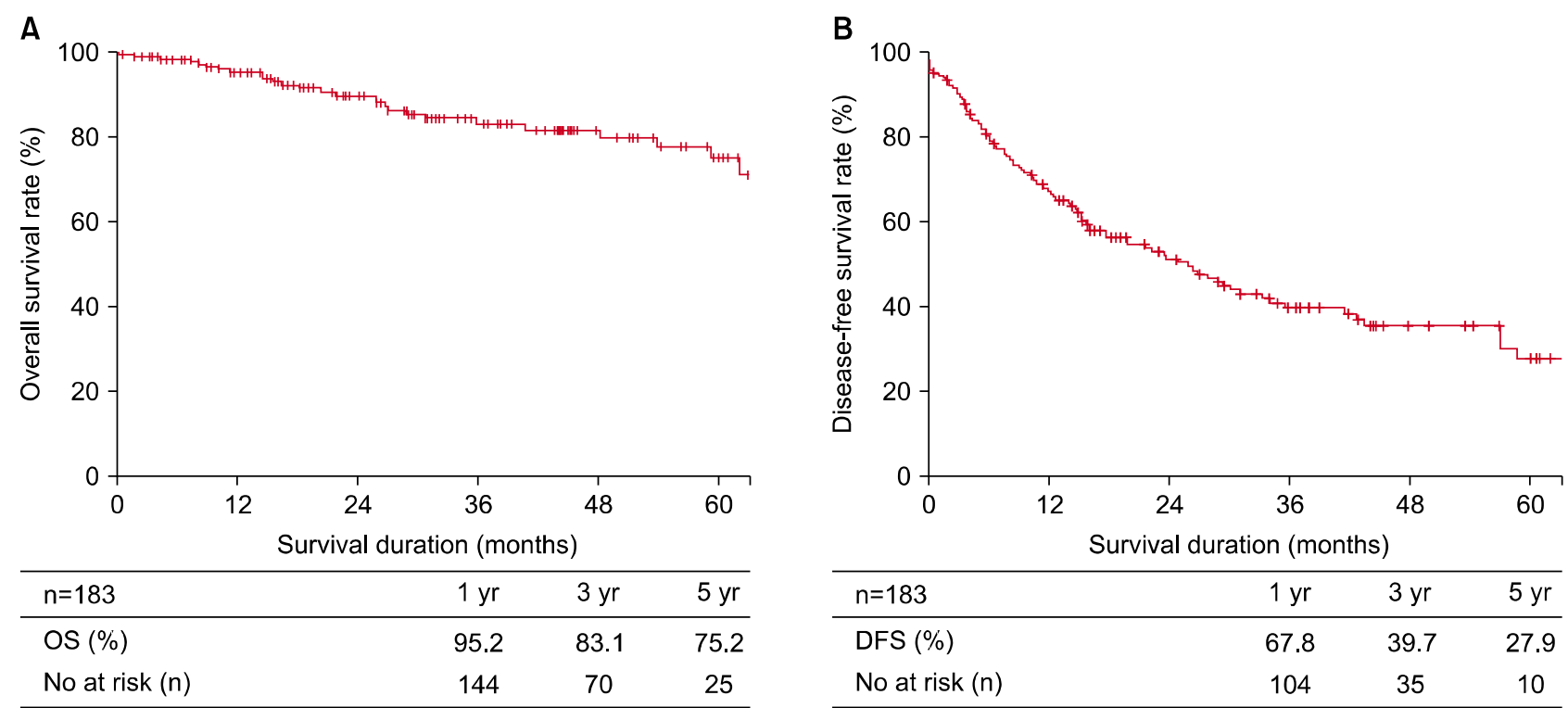

Fig. 1. (A) Overall survival rate of the whole cohort. (B) Disease-free survival of the whole cohort.
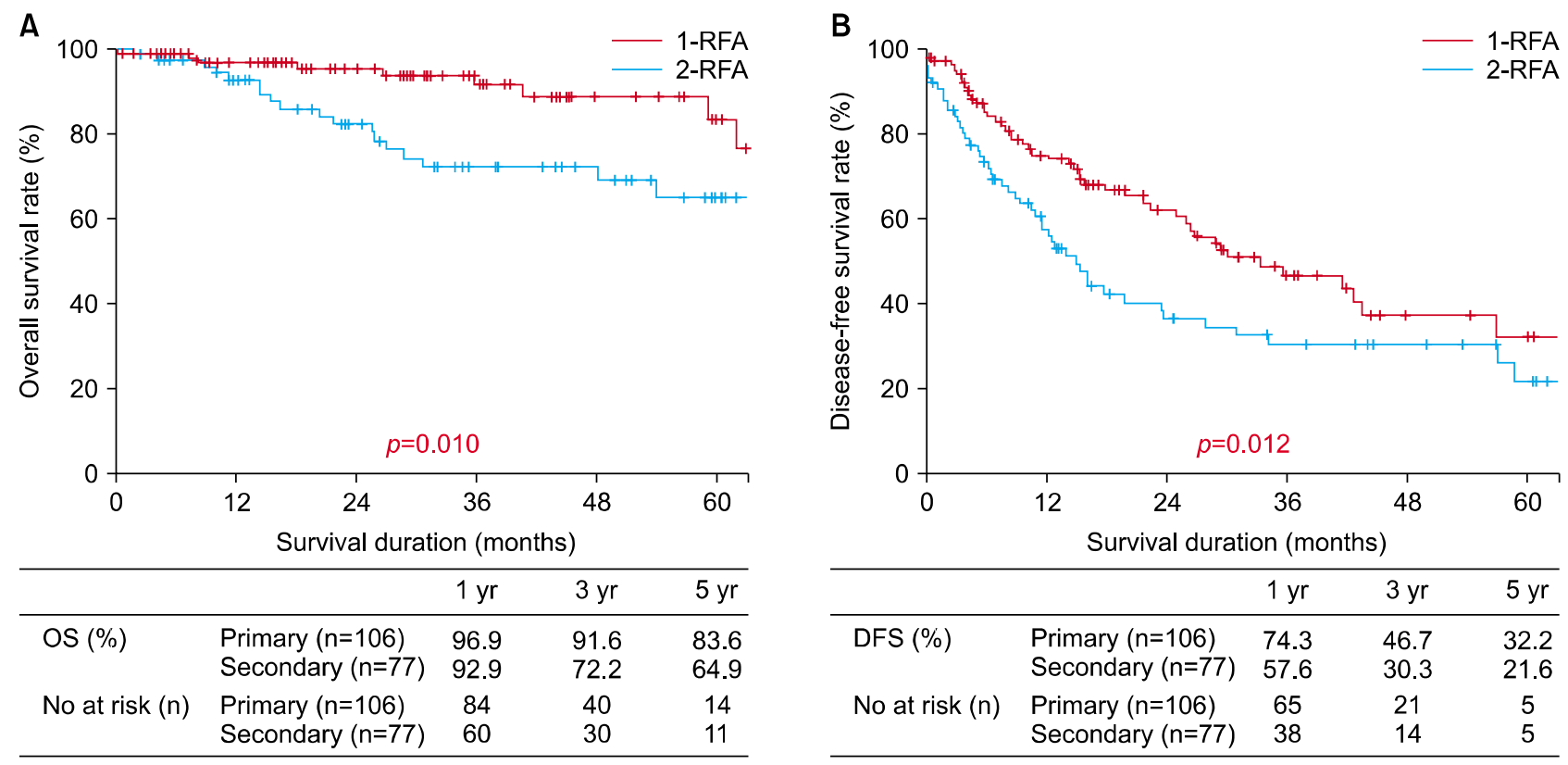

Fig. 2. (A) Overall survival rate between the 1-RFA and 2-RFA groups. (B) Disease-free survival rate between the 1-RFA and 2-RFA groups.

in Table 1. According to whether RFA was done as a primary or secondary treatment, $106(57.9 \%)$ and 77 (42.1\%) patients were categorized into the 1- and 2-RFA groups, respectively. Most preoperative parameters were not significantly different between the two groups, but the 2-RFA group showed a significantly higher proportion of male $(67.9 \%$ in 1 -RFA group versus $83.1 \%$ in 2 -RFA group; $p=0.020$ ), whereas the preoperative level of serum albumin was slightly higher in the 1 -RFA group $(3.8 \pm 0.52$ in 1-RFA group versus $3.7 \pm 0.39$ in 2-RFA group; $p=0.048$ ). There are no significant differences in the type of surgical approaches between the two groups $(p=0.079)$. The number of tumors located at segment 6 was higher in the 2-RFA group (17\% in 1-RFA group versus $29.9 \%$ in 2-RFA group; $p=0.039$ ), whereas that at segment 8 was higher in the 1-RFA group $(50 \%$ in 1 -RFA group versus $28.6 \%$ in 2 -RFA group; $p=0.004$ ). The number of tumors and largest tumor size were not significantly different be- 
tween the two groups.

Surgical outcomes are described in Table 2. Operative time was $117.6 \pm 52.6$ minutes in the whole cohort, and it did not differ between the two groups $(111.4 \pm 50.7$ in 1-RFA group versus $126.1 \pm 54.3$ in 2-RFA group; $p=0.063$ ). Postoperative hospital stay and rate of complications were also not significantly different between the two groups. One case of in-hospital mortality was found in the 1-RFA group due to postoperative liver failure and bleeding. Overall recurrence rate was $53 \%$, and the 2RFA group showed a higher recurrence rate $(46.2 \%$ in 1 -RFA group versus $62.3 \%$ in 2 -RFA group; $p=0.031$ ).
However, there were no significant differences in recurring patterns. The accuracy for RFA was $96.7 \%$ and 6 (3.3\%) patients showed incomplete ablation on postoperative CT. Of 6 patients with incomplete ablation, we could not identify the tumor by intraoperative sonography in 3 patients. The accuracy was not significantly different between two groups (1.9\% in 1-RFA group versus $5.2 \%$ in 2-RFA group; $p=0.241$ ).

\section{Survival and prognostic factors}

The median follow-up duration was 27.1 months (32.4 \pm 23.4 months). The 5-year OS and DFS rates of the

Table 3. Factors influencing overall survival

\begin{tabular}{|c|c|c|c|c|c|c|}
\hline \multirow{2}{*}{ Variables } & \multicolumn{3}{|c|}{ Univariate analysis } & \multicolumn{3}{|c|}{ Multivariate analysis } \\
\hline & HR & $95 \% \mathrm{CI}$ & $p$ value & HR & $95 \% \mathrm{CI}$ & $p$ value \\
\hline Age $>70$ years & 1.718 & $0.747-3.951$ & 0.203 & & & \\
\hline Female sex & 0.470 & $0.162-1.361$ & 0.164 & & & \\
\hline HTN & 1.152 & $0.534-2.484$ & 0.718 & & & \\
\hline $\mathrm{DM}$ & 1.544 & $0.715-3.332$ & 0.269 & & & \\
\hline TB & 0.684 & $0.093-5.055$ & 0.710 & & & \\
\hline HBV-LC & 0.430 & $0.199-0.927$ & 0.031 & 0.310 & $0.140-0.687$ & 0.004 \\
\hline HCV-LC & 1.501 & $0.604-3.731$ & 0.382 & & & \\
\hline Alc-LC & 1.930 & $0.881-4.226$ & 0.100 & & & \\
\hline Idiopathic LC & 2.450 & $0.577-10.408$ & 0.225 & & & \\
\hline Op Hx & 3.987 & $1.671-9.511$ & 0.002 & 2.359 & $0.870-6.399$ & 0.092 \\
\hline Secondary RFA & 2.759 & $1.239-6.146$ & 0.013 & 2.768 & $1.208-6.345$ & 0.016 \\
\hline $\mathrm{Hb}<10$ & 1.264 & $0.299-5.341$ & 0.750 & & & \\
\hline Plt $<100,000$ & 1.224 & $0.575-2.605$ & 0.600 & & & \\
\hline Alb $<3$ & 1.508 & $0.356-6.393$ & 0.577 & & & \\
\hline $\mathrm{TB}>2$ & 0.319 & $0.043-2.357$ & 0.263 & & & \\
\hline $\mathrm{INR}>1.2$ & 1.498 & $0.602-3.727$ & 0.385 & & & \\
\hline $\mathrm{AFP}>7$ & 1.536 & $0.696-3.389$ & 0.288 & & & \\
\hline PIVKA > $>40$ & 2.341 & $0.797-6.882$ & 0.122 & & & \\
\hline $\mathrm{ICG}>20 \%$ & 1.183 & $0.422-3.315$ & 0.749 & & & \\
\hline Multiplicity & 1.762 & $0.827-3.757$ & 0.142 & & & \\
\hline Largest size $>2 \mathrm{~cm}$ & 1.377 & $0.545-3.483$ & 0.499 & & & \\
\hline Postop stay $>5$ days & 3.103 & $1.450-6.640$ & 0.004 & 2.017 & $0.825-4.931$ & 0.124 \\
\hline Recurrence & 7.927 & $1.873-33.553$ & 0.005 & 7.468 & $1.755-31.786$ & 0.007 \\
\hline Marginal recurrence & 2.036 & $0.703-5.898$ & 0.190 & & & \\
\hline Distant meta & 3.055 & $0.721-12.947$ & 0.130 & & & \\
\hline New lesion & 1.764 & $0.802-3.879$ & 0.158 & & & \\
\hline Incomplete ablation & 4.124 & $0.951-17.880$ & 0.058 & & & \\
\hline Complications & 3.904 & $1.778-8.572$ & 0.001 & 3.486 & $1.557-7.807$ & 0.002 \\
\hline Cx G II & 2.897 & $1.163-7.215$ & 0.022 & 0.433 & $0.118-1.592$ & 0.208 \\
\hline Cx G IIIa & 2.654 & $0.355-19.864$ & 0.342 & & & \\
\hline
\end{tabular}

HTN, hypertension; DM, diabetes mellitus; HBV-LC, hepatitis B virus-associated liver cirrhosis; HCV-LC, hepatitis C virus-associated liver cirrhosis; Alc-LC, alcoholic liver cirrhosis; LC, liver cirrhosis; Hx, history; RFA, radiofrequency ablation; Hb, hemoglobin; Plt, platelet; Alb, albumin; TB, total bilirubin; INR, international normalized ratio; AFP, alpha fetoprotein; PIVKA II, protein induced by vitamin $\mathrm{K}$ absence or antagonist-II; ICG, indocyanine green; SD, standard deviation; CI, confidence interval; HR, hazard ratio 
Table 4. Factors influencing recurrence

\begin{tabular}{|c|c|c|c|c|c|c|}
\hline \multirow{2}{*}{ Variables } & \multicolumn{3}{|c|}{ Univariate analysis } & \multicolumn{3}{|c|}{ Multivariate analysis } \\
\hline & HR & $95 \% \mathrm{CI}$ & $p$-value & HR & $95 \% \mathrm{CI}$ & $p$-value \\
\hline Age $>70$ years & 1.273 & $0.805-2.014$ & 0.301 & & & \\
\hline Female sex & 0.721 & $0.447-1.163$ & 0.179 & & & \\
\hline HTN & 1.061 & $0.704-1.599$ & 0.777 & & & \\
\hline $\mathrm{DM}$ & 1.156 & $0.753-1.777$ & 0.507 & & & \\
\hline TB & 1.0440 & $0.421-2.567$ & 0.932 & & & \\
\hline HBV-LC & 0.940 & $0.620-1.424$ & 0.770 & & & \\
\hline HCV-LC & 1.381 & $0.816-2.337$ & 0.229 & & & \\
\hline Alc-LC & 1.134 & $0.709-1.815$ & 0.599 & & & \\
\hline Idiopathic LC & 1.082 & $0.342-3.424$ & 0.893 & & & \\
\hline Op Hx & 1.875 & $1.021-3.441$ & 0.043 & 2.165 & $1.172-3.998$ & 0.014 \\
\hline Secondary RFA & 1.665 & $1.112-2.493$ & 0.013 & 1.719 & $1.142-2.585$ & 2.165 \\
\hline $\mathrm{Hb}<10$ & 1.109 & $0.483-2.542$ & 0.808 & & & \\
\hline Plt $<100,000$ & 1.238 & $0.826-1.854$ & 0.301 & & & \\
\hline $\mathrm{Alb}<3$ & 1.111 & $0.451-2.737$ & 0.819 & & & \\
\hline $\mathrm{TB}>2$ & 0.814 & $0.393-1.687$ & 0.580 & & & \\
\hline INR $>1.2$ & 2.015 & $1.235-3.287$ & 0.005 & 2.102 & $1.287-3.432$ & 0.003 \\
\hline $\mathrm{AFP}>7$ & 1.519 & $0.990-2.330$ & 0.055 & & & \\
\hline PIVKA $>40$ & 1.507 & $0.836-2.716$ & 0.173 & & & \\
\hline ICG $>20 \%$ & 1.391 & $0.788-2.456$ & 0.255 & & & \\
\hline Multiplicity & 1.451 & $0.964-2.185$ & 0.074 & & & \\
\hline Largest tumor size $>2 \mathrm{~cm}$ & 0.956 & $0.562-1.625$ & 0.867 & & & \\
\hline Postop stay $>5$ days & 1.505 & $0.988-2.293$ & 0.057 & & & \\
\hline Complications & 1.563 & $0.933-2.617$ & 0.090 & & & \\
\hline Cx G II & 1.787 & $0.993-3.217$ & 0.053 & & & \\
\hline Cx G IIIa & 1.794 & $0.440-7.318$ & 0.415 & & & \\
\hline
\end{tabular}

HTN, hypertension; DM, diabetes mellitus; HBV-LC, hepatitis B virus-associated liver cirrhosis; HCV-LC, hepatitis C virus-associated liver cirrhosis; Alc-LC, alcoholic liver cirrhosis; LC, liver cirrhosis; Hx, history; RFA, radiofrequency ablation; Hb, hemoglobin; Plt, platelet; Alb, albumin; INR, international normalized ratio; AFP, alpha fetoprotein; PIVKA II, protein induced by vitamin $\mathrm{K}$ absence or antagonist-II; ICG, indocyanine green; SD, standard deviation; TB, total bilirubin; CI, confidence interval; HR, hazard ratio

whole cohort were $75.2 \%$ and $27.9 \%$, respectively (Fig. 1). The OS and DFS rates were significantly higher in the 1-RFA group (Fig. 2). The 5-year OS rates were 83.6\% and $64.9 \%$ in the 1-RFA and 2-RFA groups, respectively ( $p=0.010$ ), whereas the 5-year DFS rates were $32.2 \%$ and $21.6 \%$ in the 1-RFA and 2-RFA groups, respectively $(p=0.012)$.

Univariate analysis revealed that hepatitis B virus-associated liver cirrhosis (HBV-LC), previous history of abdominal surgery, 2-RFA, postoperative hospital stay of $>5$ days, recurrence, and surgical complications were asso- ciated with OS (Table 3). On multivariate analysis, HBV-LC, 2-RFA, recurrence, and postoperative complications were independent predictive factors for survival.

Similarly, a previous history of abdominal surgery, 2-RFA, and preoperative INR of $>1.2$ were associated with recurrence on univariate analysis. On multivariate analysis, all these variables were revealed to be independent prognostic factors for recurrence (Table 4). 


\section{DISCUSSION}

Given that surveillance tests are becoming more common for patients at risk for $\mathrm{HCC}$, the detection rate of small HCC, especially those $<2 \mathrm{~cm}$ in size has increased. ${ }^{13}$ There are many studies and meta-analyses comparing the outcomes after surgical resection and RFA for solitary HCC. ${ }^{14-23}$ However, the superiority of any method has not yet been demonstrated definitively, and RFA would be a potentially curative treatment for HCC in the early stages. ${ }^{1,24}$ In particular, because RFA can provide higher rates of complete necrosis of the target tumor than other locoregional therapies, it plays a pivotal role as a locoregional neoadjuvant therapy prior to liver transplantation. $^{25,26}$ Fontana et al. $^{27}$ first reported in 2002 a complete necrosis in $59.5 \%$ of 37 nodules treated with RFA. Subsequently, Pompili et al. ${ }^{28}$ described a complete necrosis rate of $41.3 \%$ in 46 nodules, with an increased rate for nodules $<3 \mathrm{~cm}$ in size of up to $61.9 \%$. In 2004, Mazzaferro et al. ${ }^{29}$ reported a complete necrosis in $55 \%$ of 60 nodules, which increased to $63 \%$ when the nodules were $<3 \mathrm{~cm}$ in diameter. In our study, the complete ablation rate was only $96.7 \%$ among all patients (183), and marginal recurrence was found in $8.2 \%$ of the patients during the entire follow-up period. This result may not be worse than the previous studies. ${ }^{15}$

The 1-, 3-, and 5-year OS for the entire cohort were $95.2 \%, 83.1 \%$, and $75.2 \%$, respectively. These results are much better than a previous multicenter study reported by Pompili et al. ${ }^{17}$ The main reason is thought to be that the current study included only the patients who received IO-RFA. The 1-, 3-, and 5-year DFS of all patients were $67.8 \%, 39.7 \%$, and $27.9 \%$, respectively. The DFS rate is much worse than the OS rate, indicating that all patients had underlying liver cirrhosis, which leads to a high relapse rate, but there were still effective treatment modalities that can improve survival after recurrence.

The 1-RFA group showed significantly higher OS and DFS rates than the 2-RFA group, which could be due to the fact that all patients in the 2-RFA group had recurrence after previous treatments, such as surgical resection, TACE, and RFA. Furthermore, the recurrence rate following IO-RFA was also significantly higher in the 2-RFA group. In patients who had recurrence, the next treatment could extend the survival duration, but the tu- mors were more likely to recur again. It was found that 2-RFA and recurrence were independent prognostic factors for poor survival in the multivariate analysis, which can support the abovementioned findings.

Among the entire cohort, three cases of Clavian-Dindo grade IIIa complications and one case of in-hospital mortality due to hepatic failure. However, surgical resection would be more strongly associated with major complications than RFA, suggesting that RFA might be safer than surgical resection. ${ }^{31}$

Moreover, HBV-LC was found to be associated with survival by multivariate analysis. Non-HBV-LC was a negative risk factor for long-term survival. Previous studies reported a significant association between antiviral treatment and the prognosis of HCC. ${ }^{32}$ Antiviral agents improve liver function, fibrosis, and prognosis of patients with chronic HBV infection. In particular, antiviral treatment has been reported to decrease the occurrence and the recurrence of $\mathrm{HCC}$ by reducing $\mathrm{HBV}$ DNA. ${ }^{33-35}$ In the whole cohort, $61.7 \%$ had HBV-LC in our study.

Contrary to other studies, ${ }^{36-38}$ incomplete ablation, tumor number, tumor size, and serum AFP levels were not related to survival. This is probably because of the relatively small number of patients included in our study.

This study has several limitations. First, because it had a retrospective and non-randomized nature, some degree of selection bias was involved. Moreover, only the patients who underwent IO-RFA were included; thus, the data of other patients who received surgical resection, TACE, and percutaneous RFA except IO-RFA were not collected. This would hinder the generalization of the results of the current study. To strengthen the validity of these findings, a large-scale randomized clinical trial is required. Second, there may have been some differences in the types of electrodes and RFA techniques used, and these could be potential confounders.

In conclusion, therapeutic outcomes of IO-RFA were revealed to be comparable to those of surgical resection. Additionally, 1-RFA might be an alternative treatment for naïve HCC in patients with uncompensated liver function and severe comorbidities.

\section{ORCID}

Jongduk Kwon: https://orcid.org/0000-0001-5189-9130 
Kwang-Sik Chun: https://orcid.org/0000-0002-1530-8759

In-Sang Song: https://orcid.org/0000-0001-8314-3346

Seok-Hwan Kim: https://orcid.org/0000-0003-0209-0444

Sunjong Han: https://orcid.org/0000-0002-1235-7459

\section{AUTHOR CONTRIBUTIONS}

Conceptualization: Jongduk Kwon. Data curation: Jongduk Kwon, Sunjong Han. Formal analysis: Jongduk Kwon, Kwang-Sik Chun, In-Sang Song, Seok-Hwan Kim, Sunjong Han. Funding acquisition: Kwang-Sik Chun. Methodology: Jongduk Kwon, Kwang-Sik Chun, Sunjong Han. Project administration: Kwang-Sik Chun. Visualization: Jongduk Kwon. Writing - original draft: Jongduk Kwon, Sunjong Han. Writing - review \& editing: Jongduk Kwon, Kwang-Sik Chun, Sunjong Han.

\section{REFERENCES}

1. European Association for Study of Liver; European Organisation for Research and Treatment of Cancer. EASL-EORTC clinical practice guidelines: management of hepatocellular carcinoma. Eur J Cancer 2012;48:599-641.

2. Jemal A, Bray F, Center MM, Ferlay J, Ward E, Forman D. Global cancer statistics. CA Cancer J Clin 2011;61:69-90.

3. Siegel R, Ma J, Zou Z, Jemal A. Cancer statistics, 2014. CA Cancer J Clin 2014;64:9-29.

4. Sung PS, Yang H, Na GH, Hwang S, Kang D, Jang JW, et al. Long-term outcome of liver resection versus transplantation for hepatocellular carcinoma in a region where living donation is a main source. Ann Transplant 2017;22:276-284.

5. Lencioni R, Cioni D, Crocetti L, Franchini C, Pina CD, Lera $\mathrm{J}$, et al. Early-stage hepatocellular carcinoma in patients with cirrhosis: long-term results of percutaneous image-guided radiofrequency ablation. Radiology 2005;234:961-967.

6. Georgiades CS, Hong K, Geschwind JF. Radiofrequency ablation and chemoembolization for hepatocellular carcinoma. Cancer $\mathrm{J}$ 2008; 14:117-122.

7. Xu Q, Kobayashi S, Ye X, Meng X. Comparison of hepatic resection and radiofrequency ablation for small hepatocellular carcinoma: a meta-analysis of 16,103 patients. Sci Rep 2014;4: 7252.

8. N'Kontchou G, Mahamoudi A, Aout M, Ganne-Carrié N, Grando V, Coderc E, et al. Radiofrequency ablation of hepatocellular carcinoma: long-term results and prognostic factors in 235 Western patients with cirrhosis. Hepatology 2009;50:1475-1483.

9. Lee DH, Lee JM, Lee JY, Kim SH, Yoon JH, Kim YJ, et al. Radiofrequency ablation of hepatocellular carcinoma as first-line treatment: long-term results and prognostic factors in 162 patients with cirrhosis. Radiology 2014;270:900-909.

10. Kocabayoglu P, Piras-Straub K, Gerken G, Paul A, Herzer K. Expression of fibrogenic markers in tumor and tumor-surrounding tissue at time of transplantation correlates with recurrence of hepatocellular carcinoma in patients undergoing liver transplantation. Ann Transplant 2017;22:446-454.
11. Cho JY, Choi MS, Lee GS, Sohn W, Ahn J, Sinn DH, et al. Clinical significance and predictive factors of early massive recurrence after radiofrequency ablation in patients with a single small hepatocellular carcinoma. Clin Mol Hepatol 2016;22:477486.

12. Meniconi RL, Komatsu S, Perdigao F, Boëlle PY, Soubrane O, Scatton O. Recurrent hepatocellular carcinoma: a Western strategy that emphasizes the impact of pathologic profile of the first resection. Surgery 2015;157:454-462.

13. Yim SY, Seo YS, Jung CH, Kim TH, Lee JM, Kim ES, et al. The management and prognosis of patients with hepatocellular carcinoma: what has changed in 20 years? Liver Int 2016;36: 445-453.

14. Hong SN, Lee SY, Choi MS, Lee JH, Koh KC, Paik SW, et al. Comparing the outcomes of radiofrequency ablation and surgery in patients with a single small hepatocellular carcinoma and well-preserved hepatic function. J Clin Gastroenterol 2005;39: 247-252.

15. Livraghi T, Meloni F, Di Stasi M, Rolle E, Solbiati L, Tinelli $\mathrm{C}$, et al. Sustained complete response and complications rates after radiofrequency ablation of very early hepatocellular carcinoma in cirrhosis: is resection still the treatment of choice? Hepatology 2008;47:82-89.

16. Hung HH, Chiou YY, Hsia CY, Su CW, Chou YH, Chiang JH, et al. Survival rates are comparable after radiofrequency ablation or surgery in patients with small hepatocellular carcinomas. Clin Gastroenterol Hepatol 2011;9:79-86.

17. Pompili M, Saviano A, de Matthaeis N, Cucchetti A, Ardito F, Federico B, et al. Long-term effectiveness of resection and radiofrequency ablation for single hepatocellular carcinoma $\leq 3 \mathrm{~cm}$. Results of a multicenter Italian survey. J Hepatol 2013;59:89-97.

18. Imai K, Beppu T, Chikamoto A, Doi K, Okabe H, Hayashi H, et al. Comparison between hepatic resection and radiofrequency ablation as first-line treatment for solitary small-sized hepatocellular carcinoma of $3 \mathrm{~cm}$ or less. Hepatol Res 2013;43:853864.

19. Zhou Z, Lei J, Li B, Yan L, Wang W, Wei Y, et al. Liver resection and radiofrequency ablation of very early hepatocellular carcinoma cases (single nodule $<2 \mathrm{~cm}$ ): a single-center study. Eur J Gastroenterol Hepatol 2014;26:339-344.

20. Ng KKC, Chok KSH, Chan ACY, Cheung TT, Wong TCL, Fung JYY, et al. Randomized clinical trial of hepatic resection versus radiofrequency ablation for early-stage hepatocellular carcinoma. Br J Surg 2017;104:1775-1784.

21. Peng ZW, Lin XJ, Zhang YJ, Liang HH, Guo RP, Shi M, et al. Radiofrequency ablation versus hepatic resection for the treatment of hepatocellular carcinomas $2 \mathrm{~cm}$ or smaller: a retrospective comparative study. Radiology 2012;262:1022-1033.

22. Wang JH, Wang CC, Hung CH, Chen CL, Lu SN. Survival comparison between surgical resection and radiofrequency ablation for patients in BCLC very early/early stage hepatocellular carcinoma. J Hepatol 2012;56:412-428.

23. Liu PH, Hsu CY, Hsia CY, Lee YH, Huang YH, Chiou YY, et al. Surgical resection versus radiofrequency ablation for single hepatocellular carcinoma $\leq 2 \mathrm{~cm}$ in a propensity score model: erratum. Ann Surg 2016;263:e77. Erratum for: Ann Surg 2016; 263:538-545.

24. Clinical practice guidelines for hepatocellular carcinoma differ between Japan, United States, and Europe. Liver Cancer 2015;4: 85-95.

25. Cucchetti A, Cescon M, Bigonzi E, Piscaglia F, Golfieri R, Ercolani G, et al. Priority of candidates with hepatocellular carcinoma awaiting liver transplantation can be reduced after successful bridge therapy. Liver Transpl 2011;17:1344-1354. 
26. Cucchetti A, Mazzaferro V, Pinna AD, Sposito C, Golfieri R, Serra C, et al. Average treatment effect of hepatic resection versus locoregional therapies for hepatocellular carcinoma. $\mathrm{Br} \mathrm{J}$ Surg 2017;104:1704-1712.

27. Fontana RJ, Hamidullah H, Nghiem H, Greenson JK, Hussain $\mathrm{H}$, Marrero J, et al. Percutaneous radiofrequency thermal ablation of hepatocellular carcinoma: a safe and effective bridge to liver transplantation. Liver Transpl 2002;8:1165-1174.

28. Pompili M, Mirante VG, Rondinara G, Fassati LR, Piscaglia F, Agnes $\mathrm{S}$, et al. Percutaneous ablation procedures in cirrhotic patients with hepatocellular carcinoma submitted to liver transplantation: assessment of efficacy at explant analysis and of safety for tumor recurrence. Liver Transpl 2005;11:1117-1126.

29. Mazzaferro V, Battiston C, Perrone S, Pulvirenti A, Regalia E, Romito R, et al. Radiofrequency ablation of small hepatocellular carcinoma in cirrhotic patients awaiting liver transplantation: a prospective study. Ann Surg 2004;240:900-909.

30. Lam A, Yoshida EJ, Bui K, Katrivesis J, Fernando D, Nelson $\mathrm{K}$, et al. Demographic and facility volume related outcomes in radiofrequency ablation for early-stage hepatocellular carcinoma. HPB (Oxford) 2019;21:849-856.

31. Lee HJ, Kim JW, Hur YH, Cho SB, Lee BC, Lee BK, et al. Conventional chemoembolization plus radiofrequency ablation versus surgical resection for single, medium-sized hepatocellular carcinoma: propensity-score matching analysis. J Vasc Interv Radiol 2019;30:284-292.e1.

32. Chen L, Zhang Q, Chang W, Du Y, Zhang H, Cao G. Viral and host inflammation-related factors that can predict the prognosis of hepatocellular carcinoma. Eur J Cancer 2012;48:1977-1987.

33. Yin J, Li N, Han Y, Xue J, Deng Y, Shi J, et al. Effect of antiviral treatment with nucleotide/nucleoside analogs on postoperative prognosis of hepatitis $\mathrm{B}$ virus-related hepatocellular carcinoma: a two-stage longitudinal clinical study. J Clin Oncol 2013;31:3647-3655.

34. Wong JS, Wong GL, Tsoi KK, Wong VW, Cheung SY, Chong $\mathrm{CN}$, et al. Meta-analysis: the efficacy of anti-viral therapy in prevention of recurrence after curative treatment of chronic hepatitis B-related hepatocellular carcinoma. Aliment Pharmacol Ther 2011;33:1104-1112.

35. Miao RY, Zhao HT, Yang HY, Mao YL, Lu X, Zhao Y, et al. Postoperative adjuvant antiviral therapy for hepatitis $\mathrm{B} / \mathrm{C}$ virus-related hepatocellular carcinoma: a meta-analysis. World J Gastroenterol 2010;16:2931-2942.

36. Shiina S, Tateishi R, Arano T, Uchino K, Enooku K, Nakagawa $\mathrm{H}$, et al. Radiofrequency ablation for hepatocellular carcinoma: 10-year outcome and prognostic factors. Am J Gastroenterol 2012;107:569-577.

37. El-Fattah MA, Aboelmagd M, Elhamouly M. Prognostic factors of hepatocellular carcinoma survival after radiofrequency ablation: a US population-based study. United European Gastroenterol J 2017;5:227-235.

38. Sparchez Z, Mocan T, Radu P, Mocan LP, Sparchez M, Leucuta DC, et al. Prognostic factors after percutaneous radiofrequency ablation in the treatment of hepatocellular carcinoma. Impact of incomplete ablation on recurrence and overall survival rates. J Gastrointestin Liver Dis 2018;27:399-407. 